\begin{tabular}{|c|c|}
\hline Title & Impact of low-temperature annealing on defect levels generated by Mg-ion-implanted GaN \\
\hline Author(s) & A kazawa, Masamichi; U etake, Kei \\
\hline Citation & $\begin{array}{l}\text { Japanese Journal of A pplied Physics (JJAP), 58, SCCB10 } \\
\text { https://doi .org/10.7567/1347-4065/ab09d5 }\end{array}$ \\
\hline Issue Date & 2019-06-01 \\
\hline DOC URL & http:/hdl.handle.net/2115/77742 \\
\hline Rights & (2019 The Japan Society of A pplied Physics \\
\hline Type & article (author version) \\
\hline File Information & A kazawa_JJAP_IWN2018_final-1.pdf \\
\hline
\end{tabular}

Instructions for use 


\section{Impact of Low-Temperature Annealing on Defect Levels Generated by Mg-Ion-Implanted GaN}

Masamichi Akazawa* and Kei Uetake

Research Center for Integrated Quantum Electronics, Hokkaido University, Sapporo 060-0813, Japan

*E-mail: akazawa@rciqe.hokudai.ac.jp

The impact of low-temperature annealing on Mg-ion-implanted GaN with a low dosage $\left(1.5 \times 10^{11} \mathrm{~cm}^{-2}\right)$ has been investigated using MOS diodes. Low-temperature annealing was carried out for $\mathrm{Mg}$-ion-implanted $\mathrm{GaN}$ in the temperature range from $400^{\circ} \mathrm{C}$ to $700^{\circ} \mathrm{C}$ before forming the insulator/semiconductor interface of the tested MOS diodes. Upon annealing, the hysteresis and the slope of the capacitance-voltage $(C-V)$ curves, which were affected by deep levels in the GaN bulk, were changed with the annealing temperature. In particular, the shape of $C-V$ curve was changed by annealing at a temperature as low as $500^{\circ} \mathrm{C}$. The $C-V$ curves were found to be reproducible by a simulation in which the dominant deep levels were assumed to be located at $0.1 \mathrm{eV}$ and $0.7 \mathrm{eV}$ below the conduction band edge. Considering the low recovery temperature and low dosage, the possibility of the existence of simple defects after implantation is discussed. 


\section{Introduction}

$\mathrm{GaN}$ has been used in the development of optoelectronic devices, especially light-emitting diodes ${ }^{1,2)}$. It is also a promising material for constructing high-power electronic devices ${ }^{3,4}$ because it has a wide bandgap, a high breakdown field, a high electron saturation velocity, and even a high electron mobility at a heterointerface with III-nitride alloys such as $\mathrm{AlGaN}$ and InAlN. To construct a high-power device, ion implantation technology is a convenient method when applicable. However, for GaN, the formation of a p-type region by ion implantation is difficult. Although $\mathrm{Mg}$ ion implantation is considered to be the most promising method of forming a p-type region, the activation ratio is usually low even if the large activation energy of $160 \mathrm{meV}^{5-7)}$ is taken into account. Recently, the successful formation of a p-type region in $\mathrm{GaN}$ by $\mathrm{Mg}$ ion implantation has been reported ${ }^{8-15)}$. Nevertheless, the achievement of the theoretical upper limit of the activation ratio, which is as high as $10 \%$, has only been reported in the case of using a particular type of rapid thermal annealing (RTA), i.e., multicycle RTA, in which the temperature was raised up to $1,350^{\circ} \mathrm{C}$ in $\mathrm{N}_{2}$ overpressure ${ }^{11)}$. Using a conventional RTA technique up to $1,250^{\circ} \mathrm{C}$, the highest activation ratio has been reported to be $2.3 \%{ }^{15)}$. To employ $\mathrm{Mg}$ ion implantation as a useful technology, a means of controlling the defects should be found. Narita et al. performed coimplantation with $\mathrm{Mg}$ and $\mathrm{H}$ ions to enhance the substitution of $\mathrm{Ga}$ by $\mathrm{Mg}$ while suppressing carrier compensation by $\mathrm{N}$ vacancies, $V_{\mathrm{N}}$, resulting in the suppression of the forward leakage current and the dispersion of current in the fabricated $p$-n junction diodes ${ }^{14)}$. On the basis of a positron annihilation spectroscopy (PAS) study, Uedono et al. found that a complex of a Ga vacancy, $V_{\mathrm{Ga}}$, and a $V_{\mathrm{N}}$ is dominant after $\mathrm{Mg}$ ion implantation and that vacancies agglomerate upon high-temperature annealing above $1,000^{\circ} \mathrm{C}^{16,17)}$. A common result among these preceding reports is that a high temperature above $1,200^{\circ} \mathrm{C}$ is necessary to control the defects and to activate the $\mathrm{Mg}$ atoms as acceptors. In addition, the dosage or concentration of the implanted $\mathrm{Mg}$ atoms was relatively high in these reports. An investigation of the impact of low-temperature annealing on defect levels in lightly implanted GaN may provide another clue to control defects.

We previously reported that a deep level located at $0.76 \mathrm{eV}$ below the conduction band edge, $E_{\mathrm{C}},\left(E_{\mathrm{C}}-0.76 \mathrm{eV}\right)$, was detected using a MOS diode fabricated on lightly 
Mg-ion-implanted $\mathrm{GaN}$ without high-temperature $\left(>1,200^{\circ} \mathrm{C}\right)$ annealing for activating $\mathrm{Mg}$ acceptors $^{18)}$. Alfieri et al. also reported the results of deep-level transient spectroscopy (DLTS) for lightly Mg-ion-implanted GaN, in which deep levels between $E_{\mathrm{C}}-0.2 \mathrm{eV}$ and $E_{\mathrm{C}}-1.2 \mathrm{eV}$ were detected before and after annealing at temperatures up to $1,000^{\circ} \mathrm{C}^{19)}$. However, the optimum annealing temperature for reducing the defect concentration has not been clarified. It is possible that another type of defect is generated by annealing, especially at the GaN surface. To clarify the thermal behavior of the defects generated by $\mathrm{Mg}$ ion implantation, the defects generated by implantation should be separated from those generated by annealing.

In this report, we investigated the impact of low-temperature annealing on the defect levels generated in lightly $\mathrm{Mg}$-ion-implanted $\mathrm{GaN}$ before high-temperature annealing using MOS structures. Since a MOS diode can provide information on the near-surface region when it is biased to an accumulation voltage, the energy levels near $E_{\mathrm{C}}$ can be detected even at room temperature. This feature makes it advantageous over a Schottky barrier diode.

\section{Experimental}

Samples were prepared as shown in Fig. 1 (a) and described as follows. A Si-doped n-GaN layer ( $3 \mu \mathrm{m}$ thick, $n=5 \times 10^{17} \mathrm{~cm}^{-3}$ ) was grown on a free-standing $\mathrm{n}^{+}-\mathrm{GaN}$ substrate via an $\mathrm{n}^{+}-\mathrm{GaN}$ buffer layer by metalorganic chemical vapor deposition. $\mathrm{Mg}$ ion implantation was carried out at room temperature with an energy of $50 \mathrm{keV}$, an angle of $7^{\circ}$, and a dosage of $1.5 \times 10^{11} \mathrm{~cm}^{-2}$. TRIM simulation results for this condition are shown in Fig. 1 (b). The maximum $\mathrm{Mg}$ concentration was estimated to be $\sim 2 \times 10^{16} \mathrm{~cm}^{-3}$. However, the concentrations of $V_{\mathrm{Ga}}$ and $V_{\mathrm{N}}$ were calculated to be much higher values of $\sim 1 \times 10^{19} \mathrm{~cm}^{-3}$ and $\sim 6 \times 10^{18} \mathrm{~cm}^{-3}$ at the maximum, respectively. Therefore, the detection of deep levels should be straightforward for the sample prepared here. After ion implantation, a 20-nm-thick $\mathrm{Al}_{2} \mathrm{O}_{3}$ layer was deposited by atomic layer deposition (ALD) using trimethylaluminum and $\mathrm{H}_{2} \mathrm{O}$ at a substrate temperature of $300^{\circ} \mathrm{C}$. Annealing was carried out at $400-800^{\circ} \mathrm{C}$ in $\mathrm{N}_{2}$ flow using an $\mathrm{Al}_{2} \mathrm{O}_{3}$ surface protection layer, which was followed by the removal of the $\mathrm{Al}_{2} \mathrm{O}_{3}$ layer by wet etching with a solution of $\mathrm{HF}: \mathrm{NH}_{4} \mathrm{~F}=1: 5$. Then, a 30-nm-thick ALD $\mathrm{Al}_{2} \mathrm{O}_{3}$ layer was deposited again, which was followed by the metallization of a top electrode of $\mathrm{Ni} / \mathrm{Au}$ to form a MOS structure and a back ohmic 
contact of Ti/Au. Finally, post-metallization annealing (PMA) for reducing the interface states $^{20,21)}$ was carried out at $300^{\circ} \mathrm{C}$ in air. For comparison, a MOS diode sample without cap annealing above $300^{\circ} \mathrm{C}$ was also prepared. This sample is hereafter referred to as the " $300^{\circ} \mathrm{C}$-annealed sample" because the ALD and PMA were done at $300^{\circ} \mathrm{C}$. Furthermore, samples without $\mathrm{Mg}$ ion implantation were also fabricated in the same process sequence. For the completed MOS diodes, capacitance-voltage $(C-V)$ measurement was carried out at a frequency of $1 \mathrm{MHz}$. Then, a simulation for reproducing the $C-V$ curves was performed to obtain information on the defect levels.

\section{Results and discussion}

\subsection{Impact of annealing on $\mathrm{n}-\mathrm{GaN}$ samples without $\mathrm{Mg}$ ion implantation}

Low-temperature annealing after ion implantation might be an efficient way of reducing the concentration of defects in the implanted region. Therefore, the thermal behavior of the defects can be investigated by annealing. However, annealing at an excessively high temperature can generate another type of defect, particularly at the GaN surface, which results in the distortion of the $C-V$ curves of the tested MOS diodes by the interface defects. To determine the upper-limit temperature, $\mathrm{n}-\mathrm{GaN}$ samples without $\mathrm{Mg}$ ion implantation were annealed.

The measured $C-V$ curves are shown in Fig. 2. The $300^{\circ} \mathrm{C}$-annealed sample without implantation showed excellent $C-V$ characteristics without hysteresis as shown in Fig. 2 (a). The shape of the $C-V$ curve is almost the same as the ideal curve (indicated by the broken lines). These excellent characteristics were obtained by PMA as reported in Refs. 20 and 21 . However, we found that annealing at $800^{\circ} \mathrm{C}$, even before the formation of the interface, deteriorated the $C-V$ characteristics, as shown in Fig. 2 (b), where a large hysteresis and a large bump appeared. The interface state density $D_{\text {it }}$ distribution was evaluated for both samples using the Terman method ${ }^{22)}$. Since the $D_{\text {it }}$ distribution of the $300^{\circ} \mathrm{C}$-annealed sample was below the detection limit in the energy range where the Terman method can be applied, the result only for the $800^{\circ} \mathrm{C}$-annealed sample is plotted in Fig. 2 (c). The $800^{\circ} \mathrm{C}$-annealed sample exhibited a high $D_{\text {it }}$ distribution with a discrete state at $0.63 \mathrm{eV}$. Usually, a U-shaped $D_{\text {it }}$ distribution in a band gap should be observed ${ }^{23-26)}$. However, when the concentration of a specific defect in the vicinity of the surface is very 
high, a discrete type of interface state can be observed ${ }^{27,28)}$. Therefore, the discrete level observed here should have originated from a surface defect generated during the $800^{\circ} \mathrm{C}$ annealing.

On the basis of these results, we determined that the annealing temperature should be lower than $800^{\circ} \mathrm{C}$. The upper-limit temperature of $800^{\circ} \mathrm{C}$ might have resulted from poly-crystallization in the $\mathrm{Al}_{2} \mathrm{O}_{3}$ layer ${ }^{29}, 30$ ). In the present sample fabrication process, however, the $\mathrm{Al}_{2} \mathrm{O}_{3}$ cap layer was removed after $800^{\circ} \mathrm{C}$ annealing. Therefore, it is highly likely that a defect was introduced in the vicinity of the GaN surface by $800^{\circ} \mathrm{C}$ annealing, and that the detected interface defect existed on the GaN side of the interface of the finally completed MOS structure. Although a $\mathrm{SiN}$ layer can be used as a cap layer at $800^{\circ} \mathrm{C}$ without generating the surface defect ${ }^{30}$, we used $\mathrm{ALD} \mathrm{Al}_{2} \mathrm{O}_{3}$ layer because the surface damage during deposition was prevented by ALD. Using plasma CVD or sputtering, the GaN surface might be damaged, which may persist after low-temperature annealing and may affect the characteristics of the completed MOS diodes. As described later, the temperature range up to $700^{\circ} \mathrm{C}$ was sufficient for investigating the thermal behavior of the defects generated by $\mathrm{Mg}$ ion implantation.

\subsection{Impact of annealing on Mg-ion-implanted GaN samples}

Next, we investigated the impact of low-temperature annealing on implanted samples. As shown in Figs. 3 (a) and (b), after annealing at $300^{\circ} \mathrm{C}$ and $400^{\circ} \mathrm{C}$, the $C-V$ characteristics have an anomalously steep region compared with the ideal curve assuming no implantation, resulting in a sharply bent shape. This cannot be explained by only assuming the existence of high-density interface states. Instead, this can be explained by the existence of a defect level that compensates the donor. Therefore, deep acceptor-like levels are considered to have existed in the bulk of the $\mathrm{Mg}$-ion-implanted GaN layer. Considering the hysteresis caused by a bias sweep of $50 \mathrm{mV} / \mathrm{s}$ (one $50 \mathrm{mV}$ step per s), the time constant for the corresponding deep levels is roughly estimated to be on the order of 1 to $100 \mathrm{~s}$. The time constant of the electron emission from a deep levels can be estimated by $^{19,31)}$

$$
\tau=\frac{1}{\sigma v_{t h} N_{C}} \exp \left(\frac{E_{C}-E_{T}}{k T}\right),
$$


where $\sigma$ is the capture cross section, $v_{\text {th }}$ is the electron thermal velocity, $N_{\mathrm{C}}$ is the effective density of states at the conduction band bottom, $E_{\mathrm{T}}$ is the energy of the deep level, $k$ is the Boltzmann constant, and $T$ is the temperature. If we consider that the measured $\sigma^{19,32-34)}$ is usually on the order of $1 \times 10^{-15} \mathrm{~cm}^{-2}$ to $1 \times 10^{-16} \mathrm{~cm}^{-2},\left(E_{\mathrm{C}}-E_{\mathrm{T}}\right)$ for the dominant deep level is roughly estimated to be $0.6-0.8 \mathrm{eV}$ below $E_{\mathrm{C}}$.

The $C-V$ curves obtained for the samples annealed at $500^{\circ} \mathrm{C}$ and $600^{\circ} \mathrm{C}$ are shown in Figs. 4 (a) and (b), respectively. In this temperature range, improved $C-V$ characteristics can be seen. The $C-V$ curves have rounded shapes, while the hysteresis is also minimized for these samples. It should be noted that annealing at a temperature as low as $500^{\circ} \mathrm{C}$ affected the electric properties of implanted GaN. Nevertheless, the anomalously steep region still existed for both $C-V$ curves. Therefore, the defects are considered to have been partially recovered in this temperature range.

Annealing at a higher temperature resulted in more pronounced changes in $C-V$ characteristics. The result for the sample annealed at $700^{\circ} \mathrm{C}$ is shown in Fig. 5, where it can be seen that the anomalously steep region has been minimized. A slight increase in hysteresis and the appearance of a small bump can be seen, which are highly likely to have resulted from the interface defect generated at the GaN surface by annealing. Therefore, a slight amount of the interface or surface defects on the GaN side were generated by annealing at $700^{\circ} \mathrm{C}$. Nevertheless, the shape of the $C-V$ curve measured for the sample annealed at $700^{\circ} \mathrm{C}$ is the most similar to the ideal curve, which means that annealing at $700^{\circ} \mathrm{C}$ is efficient for reducing the concentration of defects generated by $\mathrm{Mg}$ ion implantation. This result indicated that the concentration of the bulk defects generated by implantation were reduced at a temperature much lower than that used for activation of $\mathrm{Mg}$, which is typically above $1,200^{\circ} \mathrm{C}$.

\subsection{Simulation results to find dominant levels}

We carried out a simulation to reproduce the $C-V$ curve on a computer using a simulator developed previously by K. Nishiguchi ${ }^{21,35)}$. In our previous work $^{18)}$, we assumed a $D_{\text {it }}$ distribution and a reduction in carrier concentration to fit the experimental curve without assuming a bulk deep level. Here, the simulation was carried out by 
assuming the $D_{\text {it }}$ distribution and the deep levels in the GaN bulk. To simplify the simulation, the profile of the deep-level distribution in the bulk was assumed to be an exponential function.

The simulation result for the $300^{\circ} \mathrm{C}$-annealed sample is shown in Fig. 6 (a), where the $D_{\text {it }}$ distribution shown in Fig. 6 (b) and the profile of bulk deep levels shown in Fig. 6 (c) were assumed. Excellent fitting was obtained by the simulation without assuming a high $D_{\text {it. }}$ Here, it was necessary to assume the co-existence of a donor-like deep level at $E_{\mathrm{C}}$ $-0.1 \mathrm{eV}$ and an acceptor-like deep level at $E_{\mathrm{C}}-0.7 \mathrm{eV}$ to reproduce the measured $C-V$ curves. The existence of an acceptor-like deep level at $E_{\mathrm{C}}-0.7 \mathrm{eV}$ as the main deep level is in good agreement with a recent DLTS study, where the dominant acceptor-like deep levels were detected around $E_{\mathrm{C}}-0.7 \mathrm{eV}$ in $\mathrm{GaN}$ after $\mathrm{Mg}$ ion implantation under similar conditions $^{19)}$. In addition, a deep level at $E_{\mathrm{C}}-0.67 \mathrm{eV}$ that disappeared upon annealing at $900^{\circ} \mathrm{C}$ was also detected by DLTS for $\mathrm{N}$-implanted $\mathrm{GaN}^{36)}$, although the implanted element was not $\mathrm{Mg}$. Furthermore, our previous assumption of a deep level at $E_{\mathrm{C}}-0.76 \mathrm{eV}$ in a different type of simulation ${ }^{18}$ is also in good agreement with the current results. In Fig. 6 (c), the TRIM simulation results of $V_{\mathrm{Ga}}$ and $V_{\mathrm{N}}$ concentration profiles for the as-implanted situation shown in Fig. 1 (b) are also plotted, which is discussed later.

Excellent fitting was also obtained for the sample annealed at $700^{\circ} \mathrm{C}$, as shown in Fig. 7 (a), by assuming the $D_{\text {it }}$ distribution plotted in Fig. 7 (b) and the profile of bulk deep levels plotted in Fig. 7 (c). The $D_{\text {it }}$ distribution includes the surface defect level that was found for the sample annealed at $800^{\circ} \mathrm{C}$ without $\mathrm{Mg}$ ion implantation, as shown in Fig. 2 (b), in order to reproduce the small bump in the $C-V$ curve. It should be noted that there was no need to assume the donor-like level. The assumption of an acceptor-like deep level at $E_{\mathrm{C}}-0.7 \mathrm{eV}$ with low $D_{\mathrm{it}}$ was sufficient to fit the $C-V$ curves.

We found that the assumption of the donor-like deep level at $E_{\mathrm{C}}-0.1 \mathrm{eV}$ is not necessary to fit the experimental curve for the samples annealed at $500^{\circ} \mathrm{C}$ and higher. Consequently, it is likely that the concentration of the donor-like defects was reduced down to the detection limit upon annealing at $500^{\circ} \mathrm{C}$. On the basis of the results of an iterative simulation by assuming the same decay depth with that of the $E_{\mathrm{C}}-0.7 \mathrm{eV}$ level, the maximum donor-like-state concentration not to obstruct curve fitting is plotted in Fig. 7 (c) as an example detection limit. According to the previous reports on electron-irradiated 
$\mathrm{GaN}, V_{\mathrm{N}}$ was found to recover at $300^{\circ} \mathrm{C}$ in a PAS study ${ }^{37}$ and the deep level corresponding to $V_{\mathrm{N}}$ is located $0.1-0.2 \mathrm{eV}$ below $E_{\mathrm{C}}{ }^{38-40}$. Therefore, considering the recovery temperature and the location in the band gap, the donor-like deep level at $E_{\mathrm{C}}-0.1 \mathrm{eV}$ may be assigned to a defect related to $V_{\mathrm{N}}$. On the other hand, the concentration of acceptor-like deep levels at $E_{\mathrm{C}}-0.7 \mathrm{eV}$ was reduced by almost one order at $700^{\circ} \mathrm{C}$. Considering that the recovery temperature is as low as $700^{\circ} \mathrm{C}$ and that the dosage is low, the origin of the acceptor-like deep level might be a simple defect such as $V_{\text {Ga }}$. Actually, it has been found that $V_{\mathrm{Ga}}$ recovered at $500-800^{\circ} \mathrm{C}$ on the basis of a PAS study for electron-irradiated $\mathrm{GaN}^{37)}$. According to Fig. 6 (c), the concentration of $E_{\mathrm{C}}-0.7 \mathrm{eV}$ levels in the sample without $700^{\circ} \mathrm{C}$ annealing is comparable with that of $V_{\text {Ga }}$ calculated by the TRIM simulation for the as-implanted situation, although the thermal treatment is different. Heating at $300^{\circ} \mathrm{C}$ during ALD and PMA might have resulted in the reduction in the concentration of $V_{\mathrm{N}}$-related defects. Therefore the assignment described above is reasonable. In addition, the simulation in the present work is appropriate. However, a recent PAS study showed that the complex defect of $V_{\mathrm{Ga}}$ and $V_{\mathrm{N}}$ is dominant after $\mathrm{Mg}$ ion implantation ${ }^{16,17}$, although the dosage is much higher than that in this work. Therefore, the complex defect cannot be completely ruled out at this stage.

\section{Conclusions}

The impact of low-temperature annealing on Mg-ion-implanted GaN with a low dosage $\left(1.5 \times 10^{11} \mathrm{~cm}^{-2}\right)$ was investigated using MOS diodes. Low-temperature annealing was carried out for $\mathrm{Mg}$-ion-implanted $\mathrm{GaN}$ in the temperature range from $400^{\circ} \mathrm{C}$ to $700^{\circ} \mathrm{C}$ before the formation of the insulator/semiconductor interface of the tested MOS diodes. The $C-V$ characteristics, which were affected by deep levels in the GaN bulk, changed with the annealing temperature. In particular, the shape of $C-V$ curve was changed by annealing at a temperature as low as $500^{\circ} \mathrm{C}$. We found by the simulation of the $C-V$ curves that the deep levels at $E_{\mathrm{C}}-0.1 \mathrm{eV}$ and at $E_{\mathrm{C}}-0.7 \mathrm{eV}$ explained the observed phenomena. Considering the low recovery temperature and low dosage, the possibility of the existence of simple defects after implantation was discussed.

\section{Acknowledgments}


The authors appreciate Dr. T. Narita of Toyota Central Research Labs. for providing the GaN epitaxial wafers. This research is supported by the Ministry of Education, Culture, Sports, Science and Technology (MEXT), Japan, through its "Program for research and development of next-generation semiconductor to realize energy-saving society." 


\section{References}

1) H. Amano, M. Kito, K. Hiramatsu and I. Akasaki, Jpn. J. Appl. Phys. 28, L2112 (1989).

2) S. Nakamura, T. Mukai and M. Senoh, Appl. Phys. Lett. 64, 1687 (1994).

3) T. Kachi, Jpn. J. Appl. Phys. 53, 100210 (2014).

4) H. Amano et al., J. Phys. D, Appl. Phys. 51, 163001 (2018).

5) I. Akasaki, H. Amano, M. Kito and K. Hiramatsu, J. Lumin. 48 \& 49, 666 (1991).

6) T. Tanaka, A. Watanabe, H. Amano, Y. Kobayashi, I. Akasaki, S. Yamazaki and M. Koike, Appl. Phys. Lett. 65, 593 (1994).

7) W. Götz, N. M. Johnson, J. Walker, D. P. Bour and R. A. Street, Appl. Phys. Lett. 68, 667 (1996).

8) B. N. Feigelson, T. J. Anderson, M. Abraham, J. A. Freitas, J. K. Hite, C. R. Eddy and F. J. Kub, J. Cryst. Growth 350, 21 (2012).

9) T. J. Anderson, B. N. Feigelson, F. J. Kub, M. J. Tadjer, K. D. Hobart, M. A. Mastro, J. K. Hite and C. R. Eddy, Electron. Lett. 50, 197 (2014).

10) J. D. Greenlee, T. J. Anderson, B. N. Feigelson, K. D. Hobart and F. J. Kub, Phys. Status Solidi A 212, 2772 (2015).

11) T. J. Anderson, J. D. Greenlee, B. N. Feigelson, J. K. Hite, K. D. Hobart and F. J. Kub, IEEE Trans. Semicond. Manuf. 29, 343 (2016).

12) K. Nomoto, K. Takahashi, T. Oikawa, H. Ogawa, T. Nishimura, T. Mishima, H. G. Xing and T. Nakamura, ECS Trans. 69, 105 (2015).

13) T. Oikawa, Y. Saijo, S. Kato, T. Mishima and T. Nakamura, Nuclear Instruments and Methods in Physics Research B 365, 168 (2015).

14) T. Narita, T. Kachi, K. Kataoka and T. Uesugi, Appl. Phys. Exp. 10, 016501 (2017).

15) T. Niwa, T. Fujii and T. Oka, Appl. Phys. Express 10, 091002 (2017).

16) A. Uedono, S. Takashima, M. Edo, K. Ueno, H. Matsuyama, H. Kudo, H. Naramoto and S. Ishibashi, Phys. Status Solidi B 252, 2794 (2015).

17) A. Uedono, S. Takashima, M. Edo, K. Ueno, H. Matsuyama, W. Egger, T. Koschine, C. Hugenschmidt, M. Dickmann, K. Kojima, S.F. Chichibu and S. Ishibashi, Phys. Status Solidi B 255, 1700521 (2018).

18) M. Akazawa, N. Yokota and K. Uetake, AIP Advances 8, 025310 (2018). 
19) G. Alfieri, V.K. Sundaramoorthy and R. Micheletto, J. Appl. Phys. 123, 205303 (2018).

20) S. Kaneki, J. Ohira, S. Toiya, Z. Yatabe, J. T. Asubar and T. Hashizume, Appl. Phys. Lett. 109, 162104 (2016).

21) K. Nishiguchi, S. Kaneki, S. Ozaki and T. Hashizume, Jpn. J. Appl. Phys. 56, 101001 (2017).

22) S. M. Sze and K. K. Ng, Physics of Semiconductor Devices (Wiley, Hoboken, NJ, 2007) 3rd ed., Chap. 4.

23) H. Hasegawa and H. Ohno, J. Vac. Sci. \& Technol. B 4, 1130 (1986).

24) H. Hasegawa and M. Akazawa, Appl. Surf. Sci 254, 8005 (2008).

25) C. Mizue, Y. Hori, M. Miczec and T. Hashizume, Jpn. J. Appl. Phys. 50, 021001 (2011).

26) M. Matys, B. Adamowicz, A. Domanowska, A. Michalewicz, R. Stoklas, M. Akazawa, Z. Yatabe and T. Hashizume, J. Appl. Phys. 120, 225305 (2016).

27) T. Sawada, K. Numata, S. Tohdoh, T. Saitoh and H. Hasegawa, Jpn. J. Appl. Phys. 32, $511(1993)$.

28) T. Hashizume and R. Nakasaki, Appl. Phys. Lett. 80, 4564 (2002).

29) W. S. Yang, Y. K. Kim, S.-Y. Yang, J. H. Choi, H. S. Park, S. I. Lee and J.-B. Yoo, Surf. Coat. Technol. 131, 79 (2000).

30) Y. Hori, C. Mizue and T. Hashizume, Jpn. J. Appl. Phys. 49, 080201 (2010).

31) P. Kamyczek, E. Placzek-Popko, E. Zielony and Z. Zytkiewicz, Material Science-Poland 31, 572 (2013).

32) P. Hacke, T. Detchprohm, K. Hiramatsu, N. Sawaki, K. Tadatomo and K. Miyake, J. Appl. Phys. 76, 304 (1994).

33) Y. Tokuda, Y. Matsuoka, H. Ueda, O. Ishigro, N. Soejima and T. Kachi, Superlattice and Microstructures 40, 268 (2006).

34) U. Honda, Y. Yamada, Y. Tokuda and K. Shiojima, Jpn. J. Appl. Phys. 51, 04DF04 (2012).

35) S. Yamada, H. Sakurai, M. Omori, Y. Osada, R. Kamimura, T. Oyobiki. K. Nishiguci, T. Hashizume and T. Kachi, presented at Int. Conf. on Materials and Systems for Sustainability 2017 (ICMaSS2017, Nagoya, Japan, Sep. 29 - Oct. 1, 2017). 
36) D. Hasse, M. Schmid, W. Kürner, A. Dörnen, V. Härle, F. Scholz, M. Burkard and H. Schweizer, Appl. Phys. Lett. 69, 2525 (1996).

37) F. Tuomisto, V. Ranki, D.C. Look and G.C. Farlow, Phys. Rev. B 76, 165207 (2007).

38) D.C. Look, G.C. Farlow, P.J. Drevinsky, D.F. Bliss and J.R. Sizelove, Appl. Phys. Lett. 83, 3525 (2003).

39) D.C. Look, Z.-Q. Fang and B. Claflin, J. Cryst. Growth 281, 143 (2005).

40) J. L. Lyons and C. G. Van de Walle, NPJ Computational Materials 12, 1 (2017). 


\section{Figure Captions}

Fig. 1. (a) Sequence of sample preparation. For comparison, samples without process (A) and/or process (B) were also fabricated. (b) TRIM simulation results for concentration of implanted $\mathrm{Mg}$, generated $V_{\mathrm{Ga}}$, and $V_{\mathrm{N}}$.

Fig. 2. Measured $C-V$ characteristics and $D_{\text {it }}$ distributions for the samples without $\mathrm{Mg}$ ion implantation. (a) $C-V$ characteristics for $300^{\circ} \mathrm{C}$-annealed sample. (b) $C-V$ characteristics for $800^{\circ} \mathrm{C}$-annealed sample. (c) $D_{\text {it }}$ distributions.

Fig. 3. Measured $C-V$ characteristics for the Mg-ion-implanted samples. (a) $300^{\circ} \mathrm{C}$-annealed sample. (b) $400^{\circ} \mathrm{C}$-annealed sample.

Fig. 4. Measured $C-V$ characteristics for the Mg-ion-implanted samples. (a) $500^{\circ} \mathrm{C}$-annealed sample. (b) $600^{\circ} \mathrm{C}$-annealed sample.

Fig. 5. Measured $C-V$ characteristics for the Mg-ion-implanted samples with annealing at $700^{\circ} \mathrm{C}$.

Fig. 6. Simulation result for $C-V$ characteristics of the implanted sample after $300^{\circ} \mathrm{C}$ annealing. (a) $C-V$ curves. (b) Assumed $D_{\text {it }}$ distribution. (c) Assumed profile of bulk deep levels in comparison with the TRIM simulation results shown in Fig. 1 (b).

Fig. 7. Simulation result for $C-V$ characteristics of the implanted sample after $700^{\circ} \mathrm{C}$ annealing. (a) $C-V$ curves. (b) Assumed $D_{\text {it }}$ distribution. (c) Assumed profile of bulk deep levels. The fine dotted line shows an example detection limit profile. 
(a)

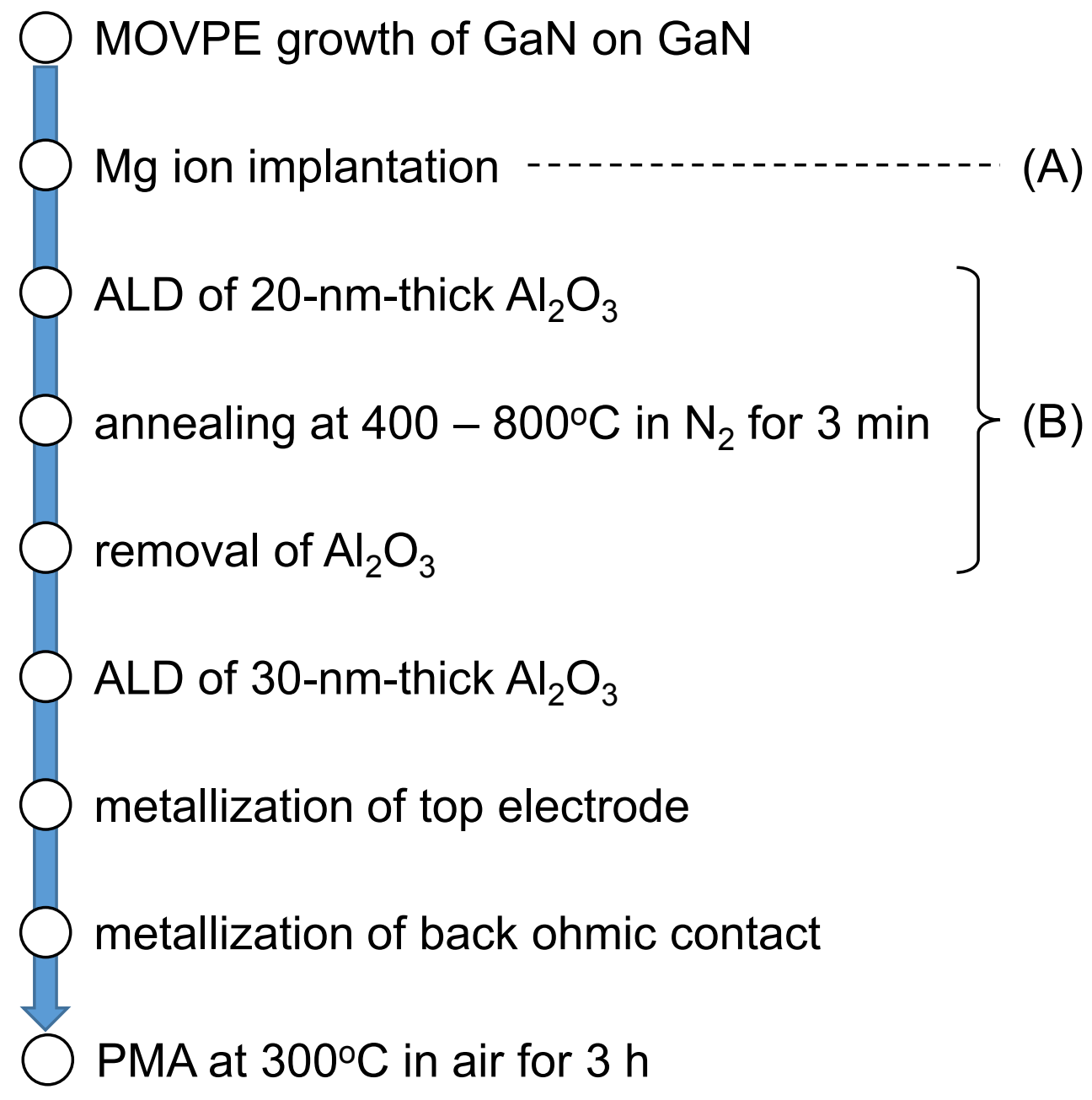

Fig.1. 


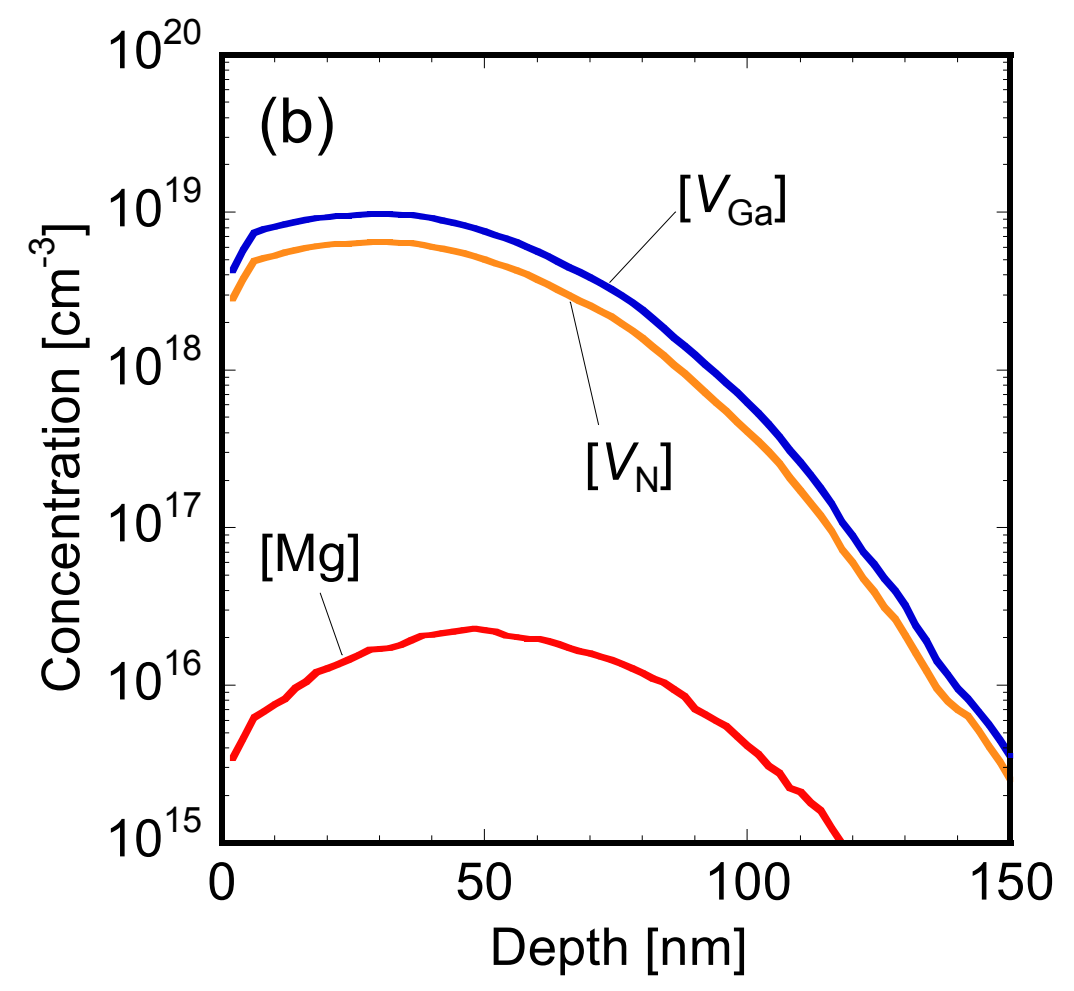

Fig. 1 

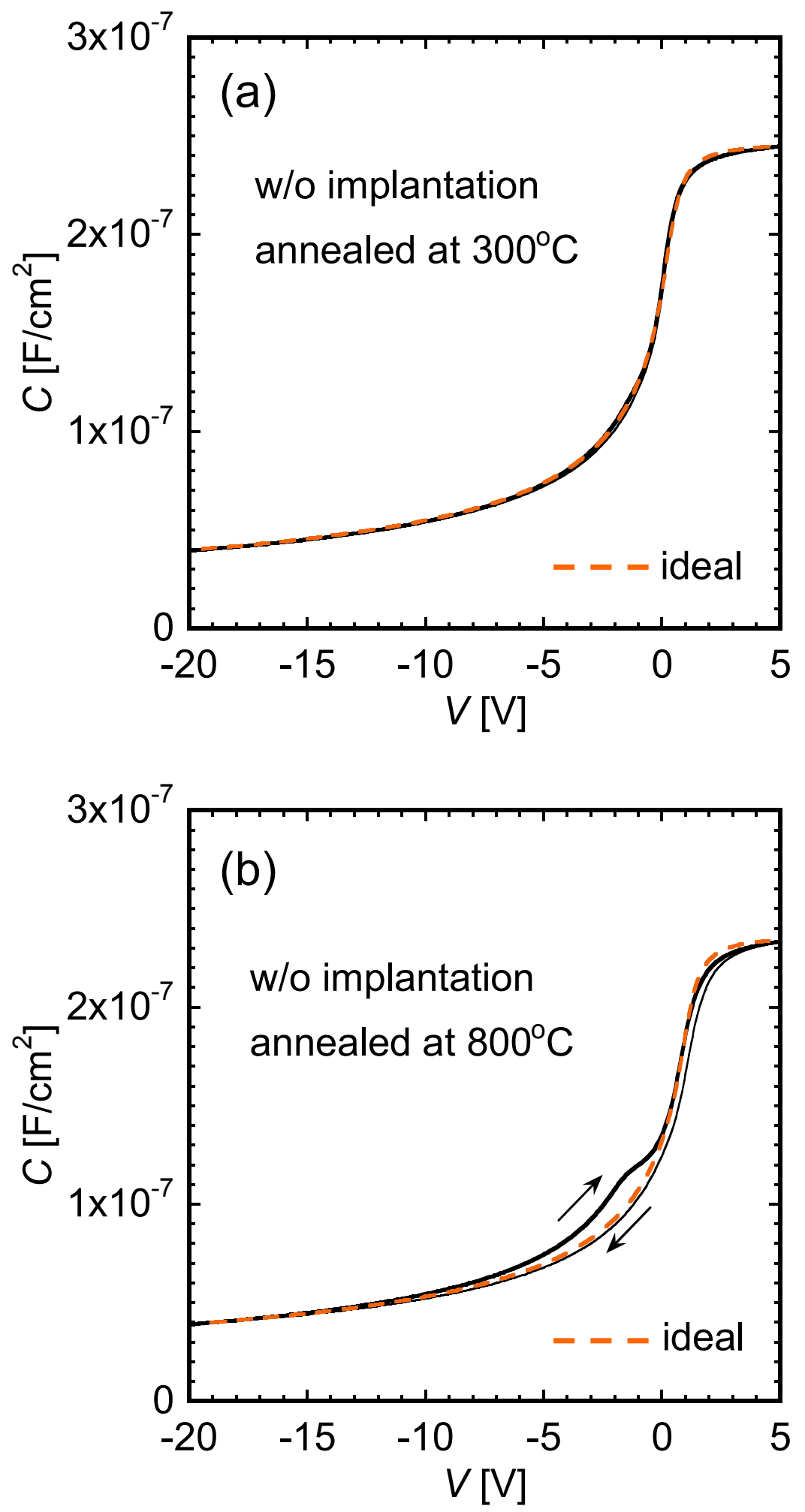

Fig. 2. 


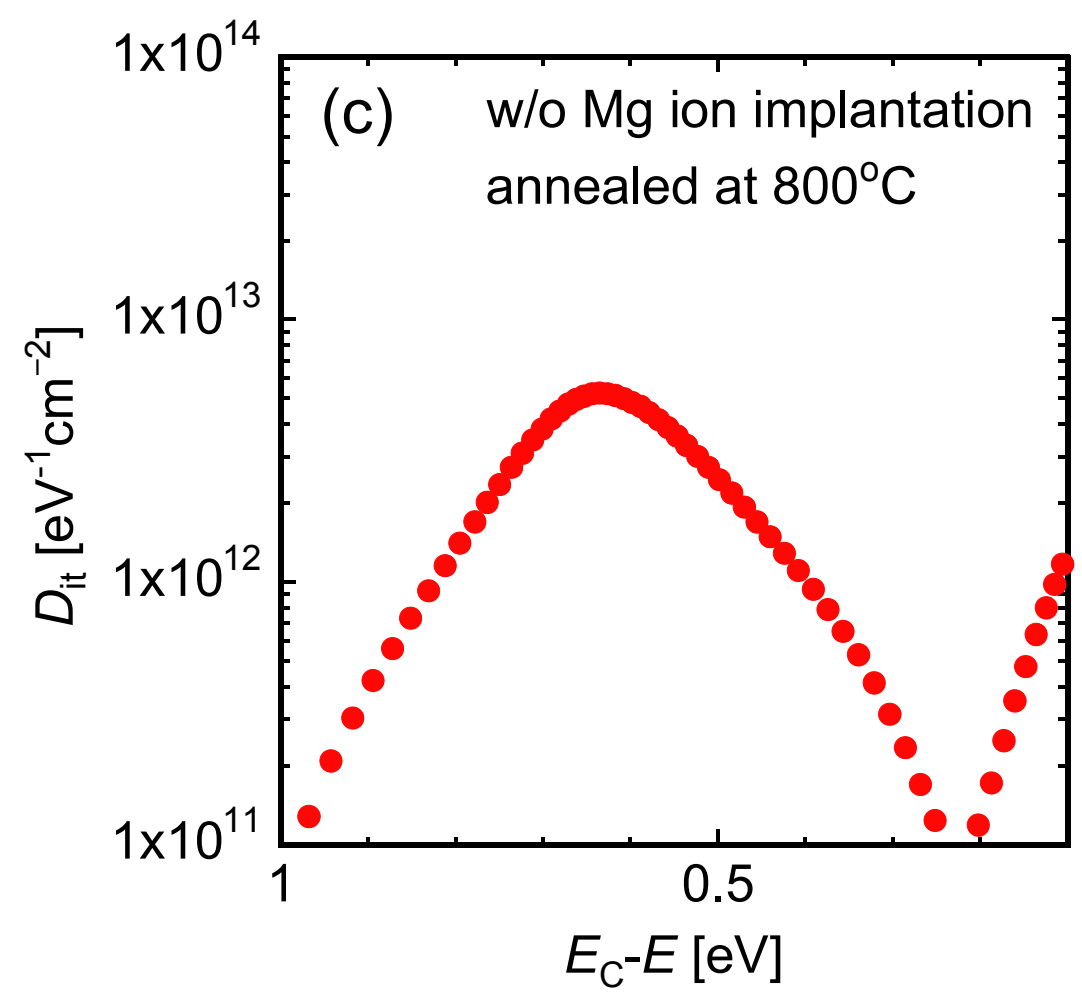

Fig. 2. 

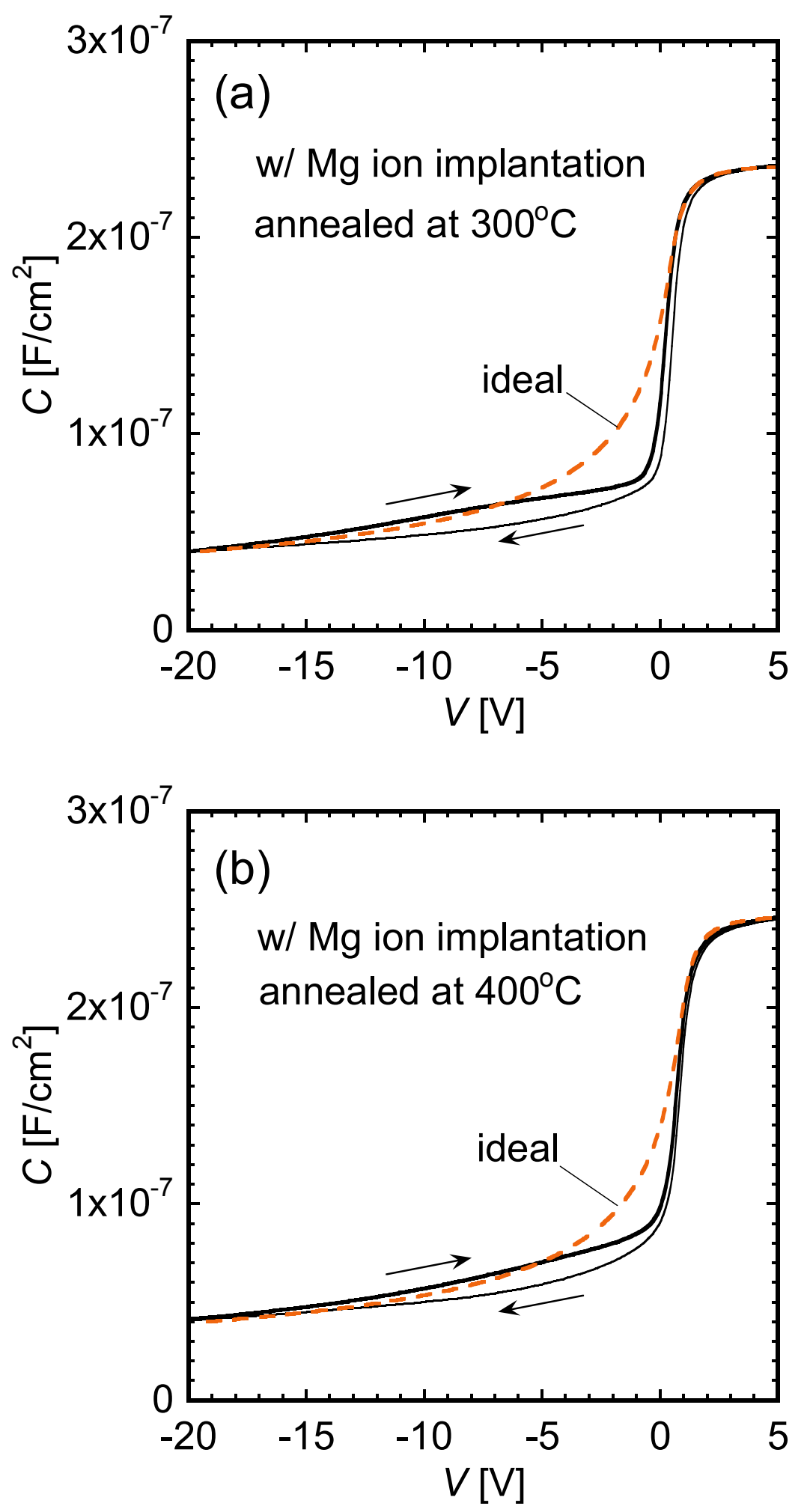

Fig. 3. 

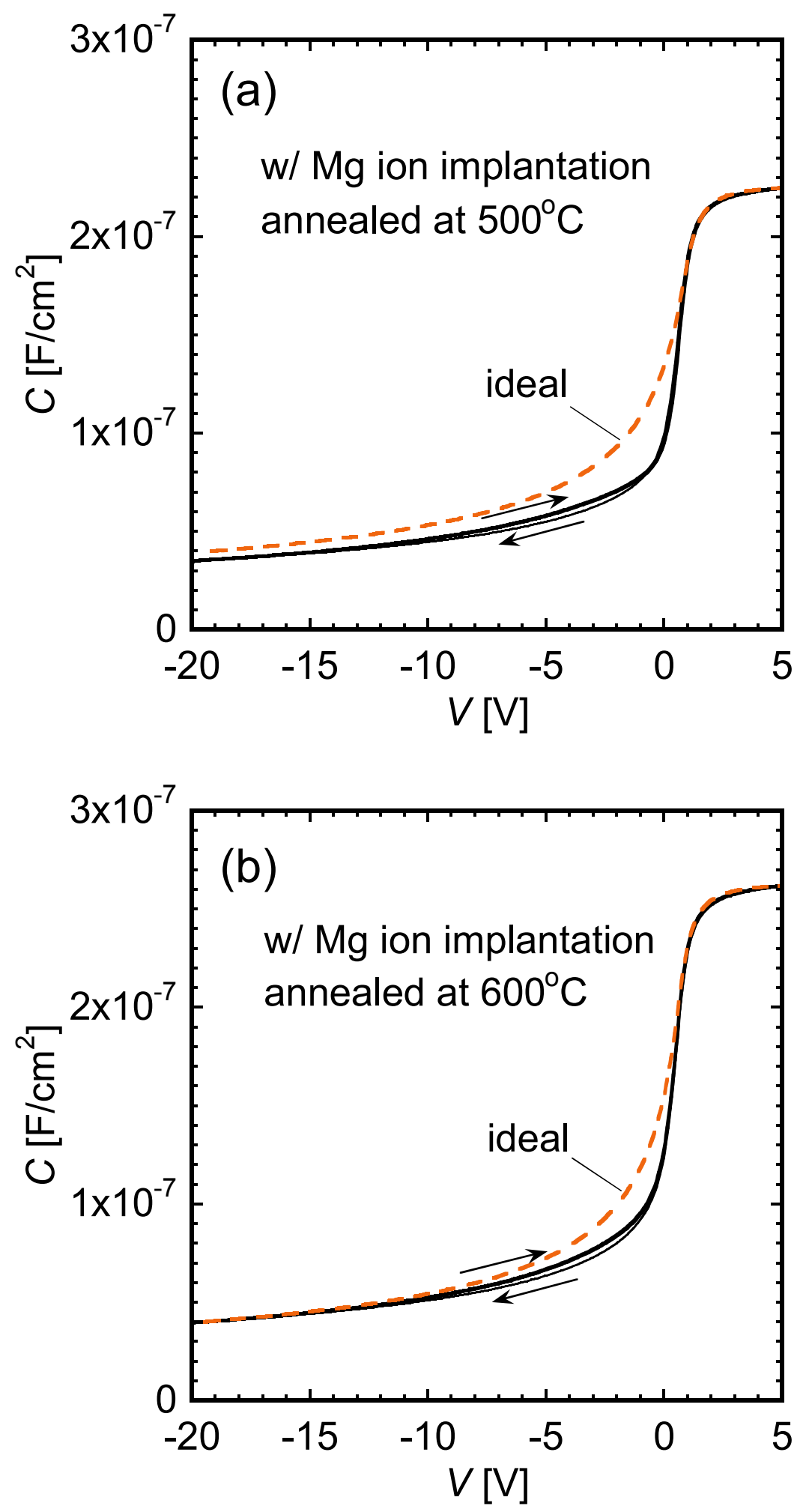

Fig. 4. 


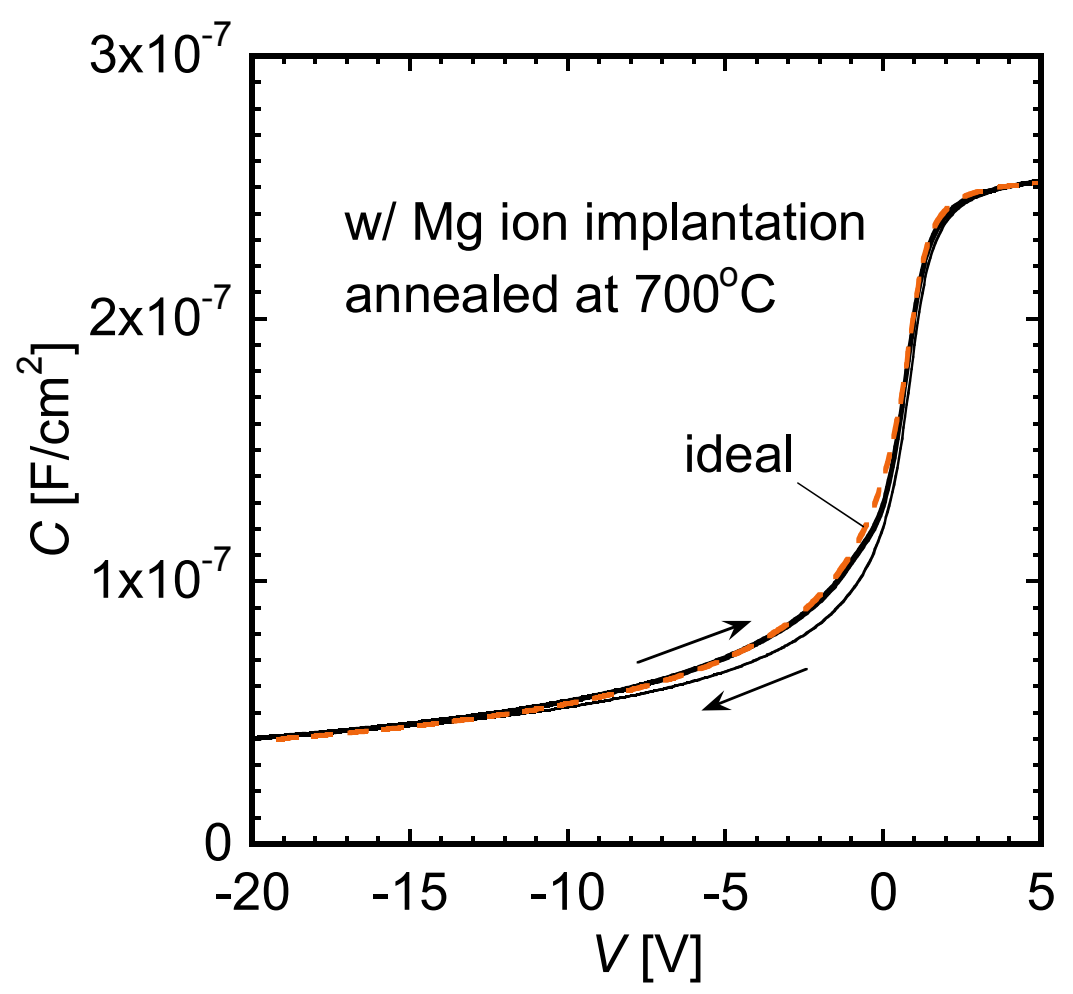

Fig. 5. 

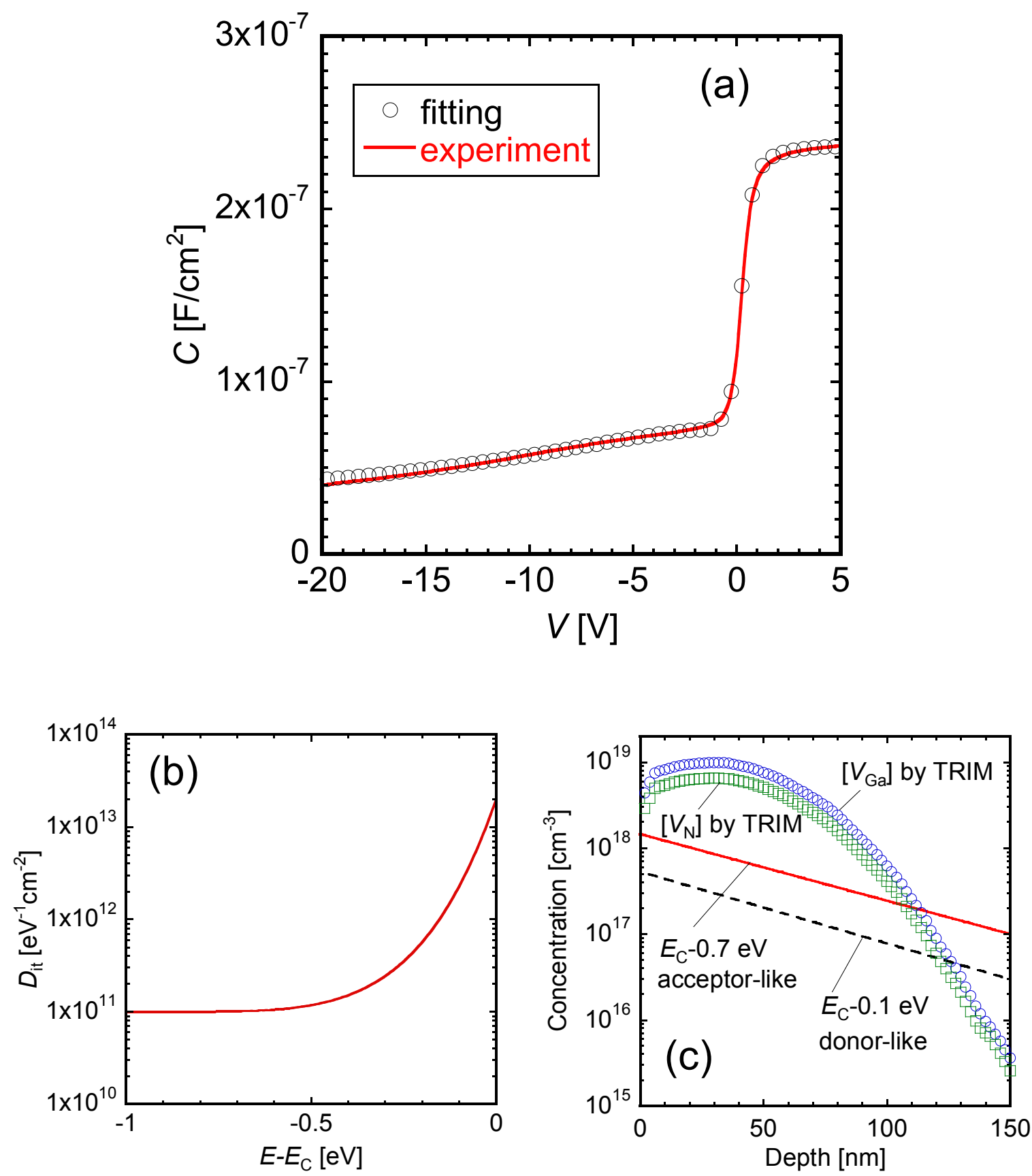

Fig. 6. 

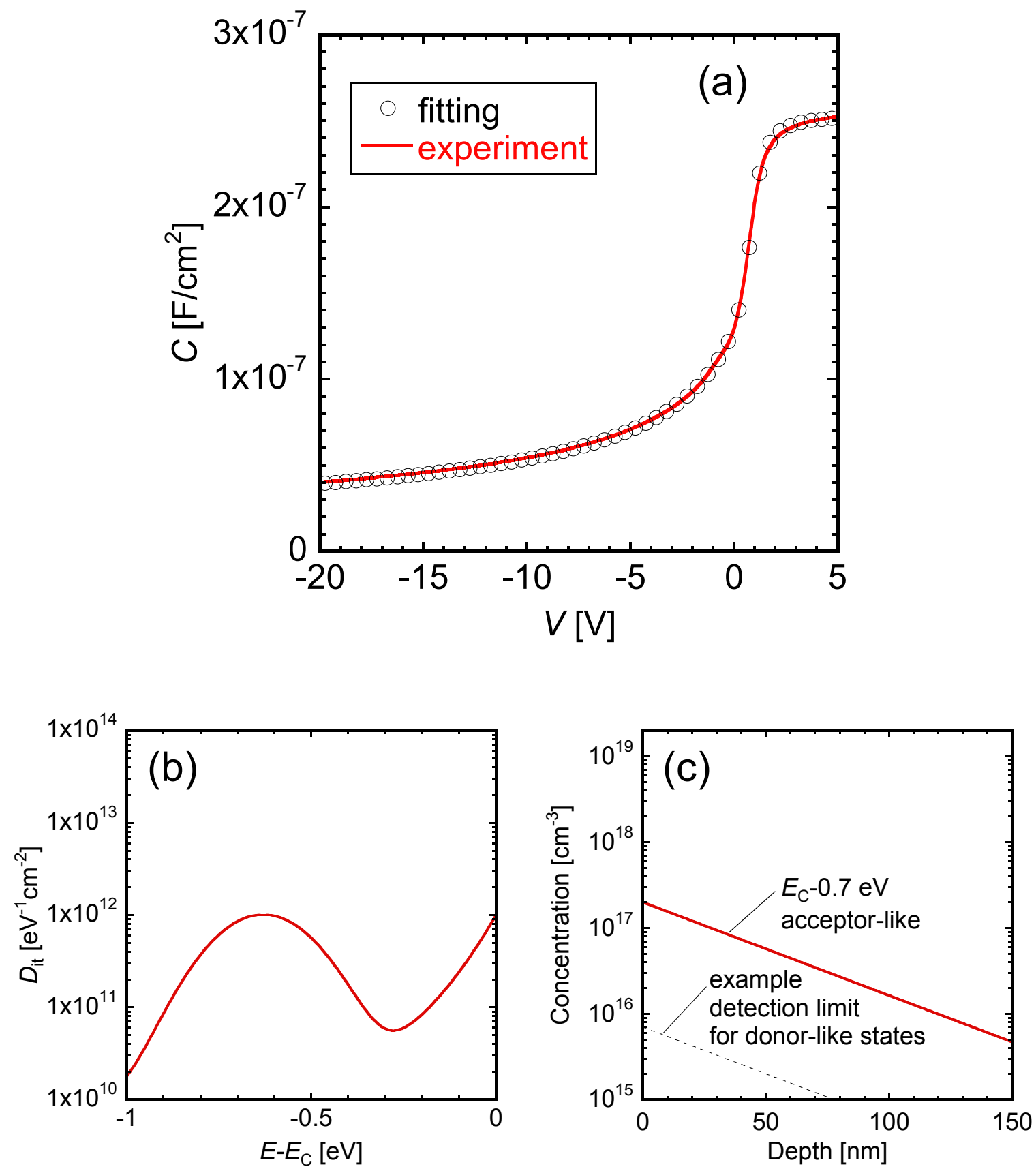

Fig. 7. 